\title{
Pemetaan Atraksi Wisata Sepanjang Jalur Penghubung (Transit Route) Badung-Bedugul
}

Luh Putu Ratih Roslandari a,1, I Made Adi Kampana a, 2

1ratihroslandari@gmail.com, 2adikampana@unud.ac.id

a Program Studi S1 Destinasi Pariwisata, Fakultas Pariwisata,Universitas Udayana, Jl. Dr. R. Goris, Denpasar, Bali 80232 Indonesia

\section{Abstract}

The development of the tourism industry currently leads to the main lines that becomes a link between tourists generating regions and tourists destination regions. This study aims to assess the current development of a tourist attraction in the transit route that can be monitored through the mapping process and the division of the tourism clusters based on tourism products and location.

The location of this research is located in the transit route along between of Badung Regency and Bedugul. The data sources are from primary and secondary data. Methods of collecting the datas are interview and observation. In this report, the data presented in the form of a map based on observations and interviews. This research's scope is limited by the concept of tourist attractions, concept of tourism clusters and concept of transit regions.

The results obtained from this research is there are mapping of tourist attractions based on administration territory along the transit route. Tourist attractions are divided into two types, natural tourist attractions and artificial tourist attractions. Tourist attractions in the transit route are concentrated based on tourism products and location tourist attraction. The tourist attractions are located in the middle of five villages that adjacently with Badung regency as tourist generating regions and Bedugul as tourist destination regions.

Keywords: Mapping, Tourist Attraction Featured, Transit Route

\section{PENDAHULUAN}

Industri pariwisata

dalam perkembangannya tidak hanya terjadi di daerah tujuan wisata dan daerah asal wisatawan namun jalur penghubung (transit route) juga dapat mengembangkan pariwisata. Masyarakat yang mempunyai jiwa kreatif ketika mampu mengembangkan potensi jalur penghubung (transit route) sebagai titik persimpangan akan memperoleh keuntungan dari wisatawan ketika singgah ke jalur penghubung (transit route). Hal ini secara tidak langsung dapat menumbuhkan perekonomian jalur penghubung (transit route) dengan cara membuka peluang-peluang bisnis seperti menjual produk-produk makanan dan minuman,kerajinan,souvenir, seni pertunjukkan dan tempat edukasi bagi wisatawan. Bahkan saat ini, telah berkembang atraksi wisata dengan jenis yang berbeda.

Pemetaan atraksi wisata di jalur penghubung (transit route) harus ditata semenarik mungkin oleh para pengelolanya agar mampu memikat wisatawan karena tidak menutup kemungkinan jalur penghubung (transit route) juga bisa menjadi daerah tujuan wisata yang baru yang dapat memberikan perkembangan pariwisata (Arjana, 2015). Kecamatan Baturiti dapat ditetapkan sebagai jalur penghubung (transit route) karena masyarakatnya menyediakan berbagai atraksi wisata. Keberadaan Kecamatan Baturiti sebagai jalur penghubung (transit route) antara Badung-Bedugul perlu dikaji penataan letak berdasarkan jenis dan konsentrasi produk wisatanya agar kedepannya dapat dijadikan sebagai tolak ukur untuk daerah lain yang ingin mengembangkan pariwisata di jalur penghubung (transit route). Berdasarkan latar belakang permasalahan yang telah dijabarkan diatas maka rumusan masalah yang diambil yaitu bagaimana pemetaan atraksi wisata di sepanjang jalur penghubung (transit route) Badung-Bedugul dan bagaimana klaster atraksi wisata berdasarkan konsentrasi produk wisata dan lokasi atraksi wisata. Tujuan artikel ini adalah untuk memetakan dan mengelompokkan atraksi wisata yang berada di jalur penghubung (transit route) sehingga mampu dikembangkan secara maksimal sebagai salah satu tempat persinggahan.

\section{TINJAUAN PUSTAKA}

\subsection{Telaah Hasil Penelitian Sebelumnya}

Masih jarangnya kajian mengenai transit route membuat terbatasnya pedoman dan panduan yang dapat diambil dari penelitian sebelumnya. Diambil dari jurnal yang memiliki 
beberapa kesamaan dengan bahasan penelitian ini untuk dijadikan tinjauan penelitian. Jurnal pertama oleh Patria (2014) yang memiliki relevansi dalam sistem pariwisata dengan model yang memfokuskan pada daerah asal wisatawan, daerah tujuan wisata dan daerah transit, jurnal ini juga meninjau secara komparatif kondisi ideal dan aktual Kabupaten Badung sebagai daerah tujuan wisata. Data yang digunakan merupakan data sekunder dari Dinas Pariwisata Kabupaten Badung.

Penelitian sebelumnya yang dilakukan oleh Prapsilo, dkk (2013) mengenai pemetaan objek wisata di Kabupaten Lampung Timur dengan menggunakan metode deskriptif eksploratif. Terdapat 10 (sepuluh) objek wisata yang dipetakan dengan data geospasial. Selanjutnya penelitian oleh Airlangga, dkk (2014) adalah pemetaan jenis objek wisata di Lampung Barat dengan hasil penelitian objek wisata digolongkan menjadi dua jenis objek wisata yaitu objek wisata alam berjumlah 5 (lima) objek dan objek wisata buatan berjumlah 2 (dua) objek. Metode penelitian yang digunakan yaitu deksriptif dengan data geospasial, teknik pengumpulan data dengan teknik observasi, wawancara dan dokumentasi.

Sampai saat ini belum pernah dilakukan penelitian mengenai pemetaan atraksi wisata di sepanjang jalur penghubung (transit route) Badung-Bedugul terutama di Desa Perean Tengah, Desa Luwus, Desa Mekarsari, Desa Baturiti dan Desa Batunya. Dengan demikian penelitian ini dapat dikatakan sebagai penelitian awal untuk mengkaji perkembangan jalur penghubung di Kecamatan Baturiti.

\subsection{Landasan Konsep dan Teori Analisis}

Dalam artikel pemetaan atraksi wisata sepanjang jalur penghubung (transit route) Badung-Bedugul ini menggunakan beberapa konsep diantaranya :

\section{Konsep Sistem Pariwisata}

Dalam konsep sistem pariwisata terdapat 3 sub atau komponen utama yang dapat dijadikan sebagai pandangan pariwisata yaitu daerah asal wisatawan, daerah tujuan wisata dan jalur penghubung (Leiper dalam Cooper, 2005). Dalam artikel ini akan membahas mengenai jalur penghubung (transit route). Transit route merupakan suatu jalur yang dijadikan sebagai tempat persinggahan sementara oleh wisatawan dan bukan merupakan tujuan akhir perjalanan wisata, tetapi wisatawan dapat menikmati jalur tersebut beberapa waktu, baik dalam perjalanan menuju ke daerah tujuan wisata maupun dalam perjalanan kembali ke daerah asal wisatawan. Dalam artikel ini, Kabupaten Badung dipilih sebagai daerah asal wisatawan mengingat Badung merupakan pusat akomodasi di Provinsi Bali. Sedangkan daerah tujuan wisata dalam artikel ini adalah kawasan wisata Bedugul.

2. Konsep Pemetaan

Pemetaan merupakan suatu proses pengumpulan data untuk dijadikan sebagai langkah awal dalam pembuatan peta, dengan menggambarkan penyebaran atraksi-atraksi wisata dalam kondisi alamiah tertentu secara meruang, memindahkan keadaan sesungguhnya ke dalam bentuk peta dasar dengan skala tertentu (Brinker, 1984). Konsep pemetaan ini digunakan untuk menandai atraksi-atraksi wisata yang berada pada transit route yang kemudian dituangkan dalam bentuk peta secara geografis.

\section{Konsep Atraksi Wisata}

Menurut Sujali (1989), ada tiga jenis atraksi wisata yaitu, atraksi wisata alam (natural resources), atraksi wisata budaya (cultural resources), Atraksi wisata buatan manusia (Man Made Resources). Konsep ini digunakan untuk mengetahui jenis atraksi yang ada di transit route.

4. Klaster Kepariwisataan

Klaster kepariwisataan merupakan pengelompokkan atraksi-atraksi wisata dalam ruang geografis yang terbatas dengan tersedianya barang, layanan, sosial dan politik, hubungan antara rantai produksi dengan budaya dan manajemen yang sangat baik dalam jaringan perusahaan dengan keunggulannya tersendiri (Beni dalam Cunha, 2005).

Klaster pariwisata dapat diartikan sebagai konsentrasi dalam ruang geografis tertentu dari komponen usaha pariwisata dan lembaga-lembaga yang menaungi kepariwisataan yang bergerak dalam suatu bidang khusus atau tertentu yang menjadi produk utama. (Sunaryo, 2013). Konsep klaster kepariwisataan digunakan dalam artikel ini untuk mengelompokkan konsentrasi atraksi wisata berdasarkan produk wisata dan konsentrasi lokasi atraksi wisata. 


\section{METODE PENELITIAN}

Lokasi yang menjadi transit route Badung-Bedugul berada dalam lingkup lima desa diantaranya Desa Perean Tengah, Desa Luwus, Desa Mekarsari, Desa Baturiti dan Desa Batunya. Metode yang digunakan yaitu deskriptif kualitatif, dimana akan terfokus dalam pemaparan-pemaparan mengenai data yang didapat melalui penelitian langsung ke lapangan yang berupa pemetaan atraksi wisata sepanjang jalur penghubung (transit route) Badung-Bedugul. Sumber data yang digunakan yaitu data primer mengenai atraksi-atraksi wisata dan data sekunder yaitu Kecamatan Baturiti dalam Angka. Teknik pengumpulan data dilakukan dengan observasi aktivitas wisatawan dan fasilitas pariwisata pada atraksi-atraksi wisata di jalur penghubung, wawancara dengan beberapa informan seperti pengelola atraksi wisata dan lima kepala desa. Teknik analisis data dilakukan dengan mengumpulkan data-data atraksi wisata dan data spasial berupa peta administratif Kecamatan Baturiti kemudian disajikan dalam bentuk peta dengan menggunakan hardware perangkat komputer dan software Photoshop. Selanjutnya peta tersebut dijelaskan secara deskriptif mengenai jenis atraksi wisata dan pengelompokkan atraksi wisata berdasarkan produk wisata dan konsentrasi lokasi.

\section{HASIL DAN PEMBAHASAN}

Kecamatan Baturiti adalah salah satu kecamatan yang berada di garis tengah penghubung antara Kabupaten Badung dengan Kabupaten Tabanan. Keberadaan Kecamatan Baturiti ditopang oleh beberapa desa yang berada di jalur utama menuju daerah tujuan wisata Bedugul. Desa tersebut diantaranya Desa Perean Tengah yang berbatasan langsung dengan Kabupaten Badung, Desa Luwus, Desa Mekarsari, Desa Baturiti dan Desa Batunya yang berbatasan dengan daerah tujuan wisata Bedugul.

Pemetaan atraksi wisata ini dilakukan di lima desa yang berada pada jalur penghubung antara daerah terluar Kabupaten Badung sampai dengan Bedugul dapat dilihat dalam gambar 1. Masing-masing desa ini memiliki atraksi wisata yang menjadi tempat singgah bagi wisatawan. menjadikan kota Pematangsiantar sebagai daerah tujuan wisata yang memang layak dikunjungi oleh wisatawan.

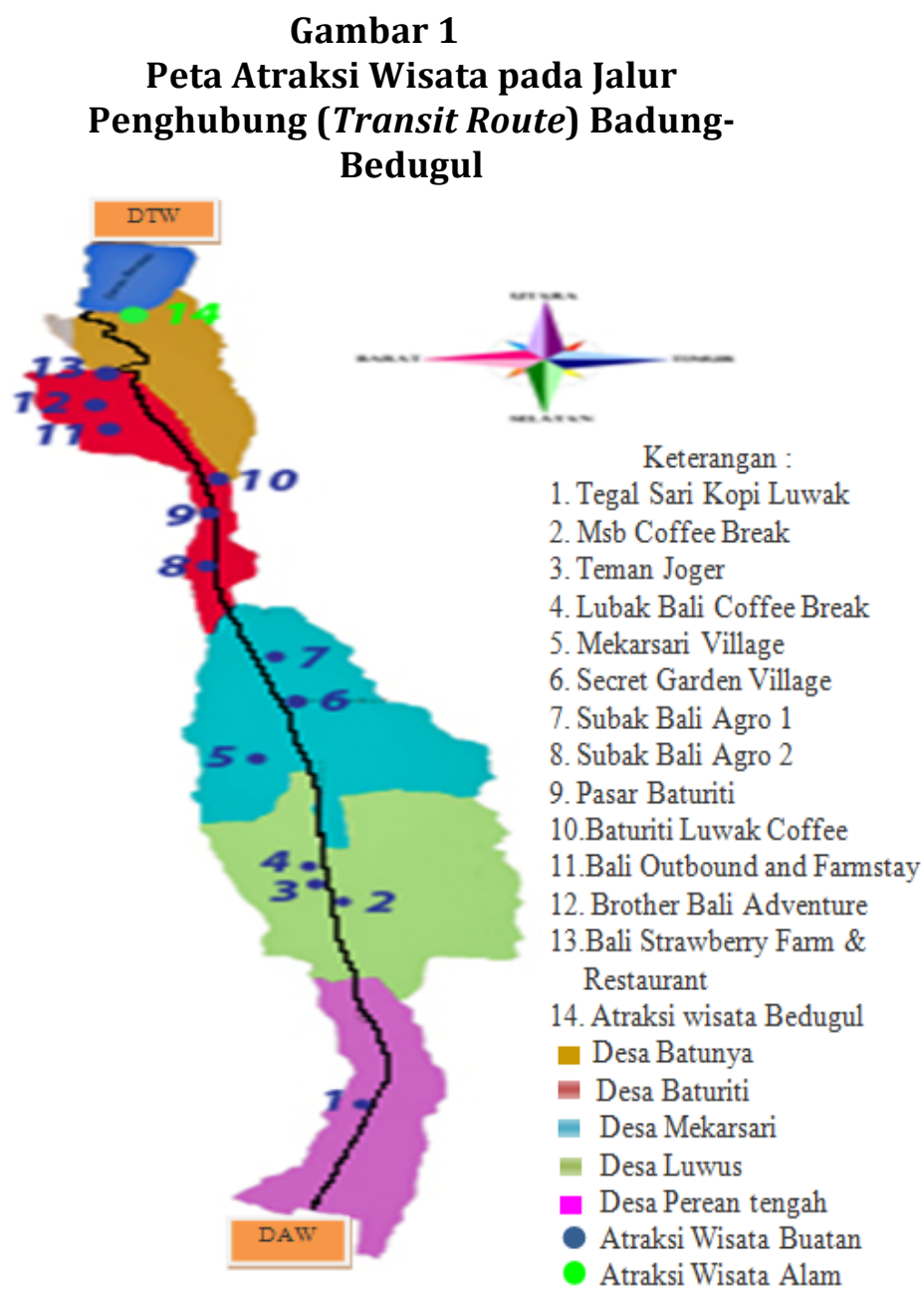

Sumber : Hasil Pengolahan Data, 2016

\subsection{Pemetaan Jenis Atraksi Wisata}

\section{Atraksi Wisata di Perean Tengah}

Desa Perean tengah ini hanya memiliki satu atraksi wisata agrotourism yaitu Tegal Sari Kopi Luwak. Tegal Sari Kopi Luwak menawarkan wisata edukasi dengan konsep memperkenalkan tumbuh-tumbuhan yang sering wisatawan santap seperti : pohon kopi, pohon kakao, pohon nangka, tumbuhan vanili dan lain-lain. Luas atraksi wisata ini yaitu 40 are dengan pembagian kebun sebesar 35 are dan restaurant \& shop 5 are. Tegal Sari Kopi Luwak ini biasanya menjadi tempat persinggahan yang sudah dipaketkan oleh agen perjalanan wisata. Paket perjalanan ini seperti daya tarik wisata Taman Ayun, Mengwi kemudian akan transit antara pukul 11.00 14.00 WITA di Tegal Sari Kopi Luwak, 
kemudian akan dilanjutkan perjalanan ke Kebun Raya Eka Karya atau Pura Ulun Danu Beratan. Atraksi wisata ini tergolong dalam jenis atraksi wisata buatan.

2. Atraksi Wisata di Desa Luwus

Desa Luwus juga berada pada jalur utama Badung-Bedugul yang dilintasi oleh wisatawan sehingga menjadi potensi transit route. Usaha yang menjadi pendukung dalam pengembangan transit route di Desa Luwus adalah agrowisata dan wisata belanja.

a. MSB Coffee Break (Merta Sari Buana) adalah salah satu atraksi wisata yang dapat dijadikan tempat transit oleh wisatawan. Lahan yang menjadi agrowisata ini seluas 60 are dengan ditanami pohon-pohon dan beberapa luwak yang dapat dilihat oleh wisatawan. Jam kedatangan wisatawan adalah pada pukul 10.00-13.00 WITA sebelum wisatawan pergi ke Bedugul. Promosi yang digunakan oleh agrowisata ini adalah dengan brosur dan memberikan informasi kepada pihak agen perjalanan.

b. Atraksi wisata selanjutnya yang berada di Desa Luwus yaitu Teman Joger. Teman Joger ini merupakan cabang dari Joger Kuta. Teman Joger adalah salah satu tempat untuk membeli oleh-oleh khas Bali yang unik dan terkenal dengan pabrik kata-kata Joger seperti "Bali Bagus, Joger Jelek". Kunjungan wisatawan ke Joger ini perharinya bisa mencapai 15 bus dan wisatawan yang dominan berkunjung adalah wisatawan domestik atau pelajar yang berasal dari luar Bali. Wisatawan domestik ini akan berkunjung ke Joger sebelum melakukan kegiatan wisata di Kebun Raya Eka Karya atau Pura Ulun Danu Beratan. Puncak kepadatan kunjungan wisatawan berada pada jam 10.0013.00 WITA.

c. Sama seperti atraksi wisata sebelumnya, atraksi wisata ini berbasiskan agrowisata yaitu Lubak Coffee Break. Atraksi ini memiliki kecenderungan aktivitas yang sama dengan agrowisata lainnya. Di dalam Lubak Coffee Break ini terdapat binatang luwak atau bahasa latinnya adalah paradoxurus hermaphroditus. Atraksi wisata ini adalah atraksi wisata yang saling berdekatan dengan Teman Joger yang memiliki jarak yaitu 400 meter.

Desa Luwus memiliki tiga atraksi wisata buatan yaitu dua agrowisata dan satu wisata belanja

\section{Atraksi Wisata di Desa Mekarsari}

Desa Mekarsari merupakan daerah paling tengah pada jalur penghubung BadungBedugul. Desa Mekarsari ini adalah merupakan desa hasil Pemekaran dari Desa Induk yaitu Desa Luwus. Atraksi wisata di Desa Mekarsari ini beragam, diantaranya :

a. Mekarsari Village

Mekarsari Village memang memiliki persamaan produk dengan agrowisata lainnya namun perbedaannya adalah dengan penyajian dan pemandangan alamnya. Keistimewaan dari Mekarsari Village adalah dapat menyantap kopi dengan melihat pemandangan Gunung Batukaru dan persawahan Desa Mekarsari. Aktivitas yang dapat dilakukan di tempat seluas 1,5 ha ini seperti, camping, trekking, cycling, membajak sawah menggunakan sapi, menamam padi, memanen padi dan melihat proses pembuatan kopi. Mekarsari Village ini menawarkan aktivitas yang lebih lama dibandingkan dengan agrowisata lainnya.

b. Secret Garden Village

Secret Garden Village ini merupakan

atraksi wisata yang berkonsepkan wisata edukasi dengan memperkenalkan budayabudaya Indonesia dari segi kecantikan dan memperlihatkan proses pembuatan kopi secara modern. Produk yang ditawarkan oleh Secret Garden Village ini seperti herborist, secret garden, beauty gourmet, fragrance bar, black eye coffee.Individual Mass Tourist

c. Subak Bali Agro 1

Subak Bali Agro ini sudah berdiri pada tahun 2011 dengan luas yaitu $1 \mathrm{Ha}$ dengan konsep coffee plantation. Aktivitas yang dapat dilakukan di atraksi wisata ini adalah pengenalan tanaman-tanaman herbal ataupun organik dan melihat luwak yang berada di kandang, melihat demo kopi atau melihat tahapan-tahapan pembuatan kopi dengan cara tradisional seperti proses pemilihan biji kopi, proses menyangrai biji kopi, proses penumbukkan biji kopi hingga menjadi serbuk kopi. Fasilitas yang ditawarkan dalam coffee break ini adalah lahan parkir yang dapat menampung 10 mobil, tempat istirahat untuk guide/driver, tempat istirahat untuk wisatawan, toilet serta outlet produk-produk dari Subak Bali Agro. Kunjungan wisatawan ke tempat ini bisa mencapai 50 mobil dengan rata-rata wisatawan 2-4 orang.

Ketiga atraksi wisata pada Desa Mekarsari termasuk dalam jenis atraksi wisata 
buatan, dimana dua diantaranya adalah agrowisata yang mengutamakan tanaman kopi.

4. Atraksi Wisata di Desa Baturiti

Desa Baturiti ini memiliki atraksi wisata terbanyak dibandingkan dengan desa-desa lainnya dengan jumlah 5 atraksi wisata.

a. Subak Bali Agro 2

Keistimewaan dari Subak Bali Agro Coffee Break ini adalah mempunyai topografi pada kemiringan yang lebih curam dan dapat menikmati keindahan pemandangan Gunung Batukaru yang terasa sangat dekat apabila menikmati hidangan kopi dan menyaksikan cara pengolahannya.

b. Pasar Baturiti

Pasar tradisional Baturiti menjadi sangat ramai dikunjungi karena berada di jalur utama daerah tujuan wisata Kebun Raya Eka Karya dan Ulun Danu Beratan. Produk yang dijual juga lebih mengarah kepada berbagai macam sayur-sayuran dan buahan-buahan segar yang berasal dari perkebunan di sepanjang Desa Baturiti. Terkadang wisatawan mancanegara khususnya hanya ingin singgah ke pasar Baturiti untuk melihat kondisi pasar tradisional di Bali serta proses transaksi yang disertai dengan tawar menawar.

c. Baturiti Luwak Coffee

Baturiti luwak Coffee mempunyai perbedaan yaitu berada pada dataran paling tinggi dari keenam agrowisata lainnya. Selain itu, keistimewaannya adalah memiliki panorama alam paling indah yang menampilkan kawasan lereng pertanian dan permukiman masyarakat Desa Baturiti. Tidak hanya menampilkan kawasan lereng, pemandangan Gunung Agung dan Gunung Baturpun sangat indah dan jelas terlihat apabila disaksikan dari Baturiti Luwak Coffee.

d. Bali Outbound and Farmstay

Bali Outbound and Farmstay ini memiliki luas 10 ha yang dijadikan sebagai tempat rekreasi keluarga dengan menyediakan aktivitas-aktivitas wisata yang berbeda dibandingkan atraksi wisata di desa sebelumnya maka dari itu BOF ini memiliki brand "A whole different onestop recreation". Aktivitas wisata yang dapat dilakukan eleh wisatawan seperti : paintball, camping, ATV, 4WD offroad, cycling, fun trail trip, outing, outbound base management training, flying fox, motor cross trekking, mini zoo memetik buah strawberry, memancing dan berkuda. Wisatawan yang melakukan kegiatan wisata di BOF ini biasanya datang setelah berwisata di Ulun Danu Beratan. Rata-rata kunjungan wisatawan yang melakukan aktivitas wisata di Bali Outbound and Farmstay adalah 1500 orang perbulan.

\section{e. Brother Bali Adventure}

Brother Bali Adventure adalah tempat rekreasi yang lebih menantang dibandingkan Bali Outbound and Farmstay karena tempat ini menyediakan permainan $A T V$ yang menguji adrenalin dengan trek yang menantang sepanjang $7 \mathrm{~km}$ dengan menempuh waktu 1,5 jam hingga 2 jam. Wisatawan akan diajak untuk berkeliling sambil menyusuri, hutan, sungai kecil, kolam air, berbagai macam kebun, jalan berlumpur jalan dan berbatu.

Terdapat lima atraksi wisata buatan di Desa Baturiti dan desa ini yang memiliki keragaman produk wisata karena tidak hanya terdapat agrowisata kopi tetapi juga pasar tradisional dan wisata olahraga.

5. Atraksi Wisata di Desa Batunya

Atraksi wisata di Desa Batunya merupakan atraksi terdekat dengan daerah tujuan wisata yaitu :

a. Bali Strawberry Farm and Restaurant

Atraksi wisata ini merupakan tempat untuk memetik buah strawberry yang segar dan dapat menikmati aneka makanan dan minuman yang terbuat dari buah strawberry. Bali Strawberry Farm and Restaurant ini biasanya dijadikan satu paket tour oleh agen perjalanan. Atraksi wisata yang masuk ke dalam paket perjalanan tersebut diantaranya: Pura Taman Ayun Mengwi, Kebun Raya Eka Karya, Pasar buah lokal Bedugul, Pura Ulun Danu Beratan, Bali Strawberry Farm and Restaurant, Alas Kedaton dan terakhir adalah Pura Tanah Lot.

b. Atraksi Wisata Bedugul

Lokasi Bedugul ini memang sangat dekat dengan Kebun Raya Eka Karya dan Ulun Danu Beratan. Atraksi wisata Bedugul ini merupakan satu-satunya atraksi wisata alam yang berada di jalur penghubung 
Badung-Bedugul. Bedugul sejatinya merupakan sebuah tempat suci atau yang berada di pinggir Danau Beratan namun pura ini disakralkan sehingga tidak ada wisatawan yang masuk ke pura tersebut. Tetapi tidak dapat dipungkiri lokasi Pura Bedugul memang dihimpit oleh akomodasi yang menyediakan restoran dan tempat rekreasi air. Aktivitas yang dapat dilakukan oleh wisatawan bila berkunjung ke atraksi wisata Bedugul yaitu : melakukan permainan water sport (menaiki speed boat, boat atap, sampan atau dayung, parasailing, jet ski, water ski, wake board, banana boat), dan melihat pemandangan alam Danau Beratan yang dikelilingi oleh perbukitan.

\subsection{Klaster Kepariwisataan}

Konsentrasi dalam memasarkan sebuah atraksi pariwisata biasanya terkendala dengan lokasi yang akan dijadikan sebagai objek dari kunjungan wisatawan karena jika lokasinya berada pada letak yang strategis maka kunjungan wisatawannya akan meningkat. Selanjutnya jika lokasinya sudah strategis maka akan berkembang atraksi-atraksi wisata lainnya. Pengelompokkan klaster atraksi wisata berdasarkan konsentrasi produk wisata dan lokasi atraksi wisata sebagai berikut :

1. Konsentrasi produk wisata

Jenis-jenis atraksi wisata biasanya didominasi oleh kesamaan aktivitas wisata untuk menarik minat wisatawan berkunjung. Hal ini terlihat dari jenis atraksi wisata yang terkosentrasi pada jalur penghubung Badung-Bedugul, hampir sama satu atraksi wisata dengan atraksi wisata lainnya yaitu agrowisata yang berjumlah 7 (tujuh) diantaranya Tegal Sari Kopi Luwak, MSB Coffee Break, lubak Bali Coffee Break, Mekarsari Village, Subak Bali Agro 1, Subak Bali Agro 2 dan Baturiti Luwak Coffee. Adanya sebuah trend dalam dunia pariwisata menginisiatif pelaku bisnis untuk membuka sebuah produk yang mereka duplikasikan dari pelaku bisnis sebelumnya.

2. Konsentrasi lokasi atraksi wisata

Berdasarkan konsentrasi lokasinya, atraksi wisata terkonsentrasi hanya dalam tiga desa yaitu Desa Luwus, Desa Mekarsari dan Desa Baturiti dalam artian ketiga desa tersebut memiliki atraksi wisata terbanyak yaitu Desa Luwus memiliki 3 (tiga) atraksi wisata, Desa
Mekarsari juga memiliki 3 (tiga) atraksi wisata dan Desa Baturiti memiliki 5 (lima) atraksi wisata. Ketiga desa ini merupakan zona tengah yang menjadi pusat konsentrasi wisatawan untuk singgah (transit).

\section{SIMPULAN DAN SARAN}

\subsection{Simpulan}

Pemetaan atraksi wisata di jalur penghubung Badung-Bedugul ini terdapat lima desa yaitu Desa Perean Tengah, Desa Luwus, Desa Mekarsari, Desa Baturiti dan Desa Batunya. Dalam lima desa ini terdapat 14 atraksi wisata dimana terbagi menjadi dua jenis yaitu: atraksi wisata alam dan atraksi wisata buatan. Atraksi wisata alam berjumlah 1 sedangkan atraksi wisata buatan berjumlah 13 . Berdasarkan konsentrasi produknya lebih mengarah pada agrowisata yang berjumlah 6 agrowisata dan berdasarkan konsentrasi lokasi atraksi wisata sepanjang jalur penghubung Kabupaten Badung-Bedugul berada pada zona tengah dari jalur tersebut yaitu Desa Luwus, Desa Mekarsari dan Desa Baturiti.

\subsection{Saran}

Berdasarkan hasil dan pembahasan yang telah dijabarkan diatas, maka saran untuk pemerintah tidak hanya mempromosikan daerah tujuan wisata yaitu Pura Ulun Danu Beratan dan Kebun Raya Eka Karya tetapi juga harus mendukung dan membantu mempromosikan pengembangan transit route di Kecamatan Baturiti sehingga akan mendatangkan wisatawan yang lebih banyak dan pemasukan Pendapatan Asli Daerah akan bertambah.

Bagi masyarakat yang sudah terlibat dalam pengelolaan transit route sebaiknya perlu diberikan edukasi agar memperoleh pengetahuan mengenai kegiatan dan fasilitas atraksi wisata sehingga pelayanan yang diberikan kepada wisatawan lebih optimal. Masyarakat lokal yang mempunyai ide maupun lahan yang belum berkembang sebaiknya membuat atraksi wisata yang berbeda sehingga dapat menarik wisatawan dan dapat mempekerjakan masyarakat lokal. Perlu adanya penambahan atraksi wisata yang berbasiskan alam karena persawahan dan 
keadaan alam di Kecamatan Baturiti masih sangat alami.

\section{DAFTAR PUSTAKA}

Airlangga, dkk. 2014. Pemetaan Objek Wisata di Wilayah Kabupaten Lampung barat Tahun 2014.

Arjana, I Gusti Bagus. 2015. Geografi Pariwisata dan Ekonomi Kreatif. Jakarta: PT RajaGrafindo Persada.

Brinker, R.C. 1984. Dasar-Dasar Pengukuran Tanah (Surveying). Jakarta: Erlangga.

Cooper, Chris and brian G. Boniface. 2005. Worldwide Destinations The Geography of Travel and Tourism. Oxford : Elsevier Butterworth-Heinemann.

Cunha, Sieglinde Kindl Da, dkk. 2005. Tourism Cluster Competitivenes and Sustainability :Proposal for a Systemic Model to Measure the Impact of Tourism on Local Development. Brazil : Brazilian Administration Review.

Patria, Teguh Amor. 2014. Tinjauan Sistem dan Elemen Pariwisata di Kabupaten Badung, Bali, melalui Sistem Pariwisata Leiper. Fakultas Ekonomi dan Komunikasi Universitas Binus. Jakarta Barat.

Prapsilo, dkk. 2013. Pemetaan dan Deskripsi Sebaran Potensi Objek Wisata di Wilayah Kabupaten Lampung Timur Tahun 2013.

Sujali. 1989. Geografi Pariwisata dan Kepariwisataan. Yogyakarta: Fakultas Geografi, Universitas Gadjah Mada.

Sunaryo, Bambang. 2013. Kebijakan Pembangunan Destinasi Pariwisata Konsep dan Aplikasinya di Indonesia. Yogyakarta : Penerbit Gava Media. 